\title{
A new two parameter Burr XII distribution: properties, cop- ula, different estimation methods, and modeling acute bone cancer data
}

\author{
M. M. Mansour ${ }^{a}$, Haitham M. Yousof ${ }^{b, *}$, Wahid A. M. Shehata ${ }^{c}$, Mohamed Ibrahim ${ }^{d}$ \\ ${ }^{a}$ Department of MIS, Yanbu, Taibah University, Saudi Arabia. \\ ${ }^{b}$ Department of Statistics, Mathematics and Insurance, Benha University, Benha, Egypt. \\ ${ }^{c}$ Department of Mathematics, Statistics and Insurance, Faculty of Business, Ain Shams University, Egypt. \\ ${ }^{d}$ Department of Applied Statistics and Insurance, Faculty of Commerce, Damietta University, Damietta, Egypt.
}

\begin{abstract}
We present a new two parameter Burr XII distribution. The new density can be right skewed with no peak, unimodal-right skewed, left skewed and symmetric. The new failure rate can be decreasing, unimodal and increasing. Properties related to the new model are derived. Simple type copula-based construction is presented for deriving some new bivariate and multivariate type distributions. The maximum likelihood estimation, Anderson Darling estimation, right tail Anderson Darling estimation and left tail Anderson Darling estimation methods are used to estimate the model parameters. A new data set is analyzed for comparing estimations methods and the competitive models.
\end{abstract}

Keywords: Burr XII distribution, copula, asymptotics, moments, maximum likelihood method, Anderson Darling. 2010 MSC: 62E10, 60E05.

(C)2020 All rights reserved.

\section{Introduction, construction, and motivation}

A random variable ( $\mathrm{rv}$ ) $\mathrm{T}$ is said to have the Burr XII (BXII) distribution if its cumulative distribution function (CDF) and probability density function (PDF) are given by

$$
\mathrm{G}_{\left(\mathrm{a}_{1}, \mathrm{a}_{2}\right)}(\mathrm{t})=1-\left(1+\mathrm{t}^{\mathrm{a}_{1}}\right)^{-\mathrm{a}_{2}}
$$

and

$$
g_{\left(a_{1}, a_{2}\right)}(t)=a_{1} a_{2} t^{a_{1}-1}\left(1+t^{a_{1}}\right)^{-a_{2}-1},
$$

\footnotetext{
*Corresponding author

Email addresses: mmmansour@taibahu.edu.sa (M. M. Mansour), haitham. yousof@fcom.bu.edu.eg (Haitham M. Yousof), wahid75maher@yahoo.com (Wahid A. M. Shehata), mohamed_ibrahim@du.edu.eg (Mohamed Ibrahim)
}

doi: $10.22436 /$ jnsa.013.05.01

Received: 2019-12-18 Revised: 2020-01-01 Accepted: 2020-01-16 
both $a_{1}$ and $a_{2}$ are shape parameters, the location and scale parameters can easily be introduced to make $\mathrm{G}_{\left(\mathrm{a}_{1}, \mathrm{a}_{2}\right)}(\mathrm{x})$ a four parameter distribution. The Burr XII distribution (BXII) originally proposed by Burr [6], it has many applications in different areas. Coming early, Tadikamalla [23] studied the BXII model and its related models. Some importand extensions of the BXII model can be cited by Zimmer et al. [27], Cordeiro et al. [10], Afify at al. [2], Altun et al. [4, 5]), Yousof et al. [25] and Yousof et al. [26] (for more details about the BXII see Burr [6-8], Burr and Cislak [9], Hatke [14], and Rodriguez [22]). In this work, we propose a new BXII, called the Burr-Hatke Logarithmic BXII distribution (BH-BXII) by using the Burr-Hatke Logarithmic G family firstly introduced by Yousof et al. [25]. Following Yousof et al. [25], the CDF of the BH-BXII model is defined by

$$
\mathrm{F}_{\left(\mathrm{a}_{1}, \mathrm{a}_{2}\right)}(x)=1-\frac{1-\left[1-\left(1+x^{\mathrm{a}_{1}}\right)^{-\mathrm{a}_{2}}\right]}{1-\log \left\{1-\left[1-\left(1+x^{\mathrm{a}_{1}}\right)^{-\mathrm{a}_{2}}\right]\right\}},
$$

the corresponding PDF to (1.2) is given by

$$
f_{\left(a_{1}, a_{2}\right)}(x)=a_{1} a_{2} x^{a_{1}-1}\left(1+x^{a_{1}}\right)^{-a_{2}-1} \frac{\left[1-\log \left\{1-\left[1-\left(1+x^{a_{1}}\right)^{-a_{2}}\right]\right\}\right]+1}{\left(1-\log \left\{1-\left[1-\left(1+x^{a_{1}}\right)^{-a_{2}}\right]\right\}\right)^{2}} .
$$

The reliability function (RF) and hazard rate function (HRF) of new BH-G family are given by

$$
\mathrm{R}_{\left(\mathrm{a}_{1}, \mathrm{a}_{2}\right)}(\mathrm{x})=\frac{1-\left[1-\left(1+x^{\mathrm{a}_{1}}\right)^{-\mathrm{a}_{2}}\right]}{1-\log \left\{1-\left[1-\left(1+x^{\mathrm{a}_{1}}\right)^{-\mathrm{a}_{2}}\right]\right\}^{\prime}},
$$

and

$$
\begin{aligned}
h_{\left(a_{1}, a_{2}\right)}(x)= & a_{1} a_{2} x^{a_{1}-1}\left(1+x^{a_{1}}\right)^{-a_{2}-1}\left[\left(1-\log \left\{1-\left[1-\left(1+x^{a_{1}}\right)^{-a_{2}}\right]\right\}\right)+1\right] \\
& \times\left\{1-\left[1-\left(1+x^{a_{1}}\right)^{-a_{2}}\right]\right\}^{-1}\left(1-\log \left\{1-\left[1-\left(1+x^{a_{1}}\right)^{-a_{2}}\right]\right\}\right)^{-1} .
\end{aligned}
$$

Let $\mathbf{c}=\inf \left\{x \mid \mathrm{F}_{\left(\mathrm{a}_{1}, \mathrm{a}_{2}\right)}(x)>0\right\}$ the asymptotics of CDF, PDF, and HRF as $x \rightarrow \mathrm{a}_{1}$ are given by

and

$$
\begin{array}{r}
F_{\left(a_{1}, a_{2}\right)}(x) \sim 1-\left(1+x^{a_{1}}\right)^{-a_{2}} \mid x \rightarrow c, \\
f_{\left(a_{1}, a_{2}\right)}(x) \sim a_{1} a_{2} t^{a_{1}-1}\left(1+t^{a_{1}}\right)^{-a_{2}-1} \mid x \rightarrow c,
\end{array}
$$

$$
h_{\left(a_{1}, a_{2}\right)}(x) \sim a_{1} a_{2} t^{a_{1}-1}\left(1+t^{a_{1}}\right)^{-a_{2}-1} \mid x \rightarrow c .
$$

The asymptotics of CDF, PDF, and HRF as $x \rightarrow \infty$ are given by

$$
\begin{aligned}
& 1-\mathrm{F}_{\left(\mathrm{a}_{1}, \mathrm{a}_{2}\right)}(\mathrm{x}) \mid \mathrm{x} \rightarrow \infty \sim-\frac{1-\left[1-\left(1+\mathrm{x}^{\mathrm{a}_{1}}\right)^{-\mathrm{a}_{2}}\right]}{\log \left\{1-\left[1-\left(1+\chi^{\mathrm{a}_{1}}\right)^{-\mathrm{a}_{2}}\right]\right\}}, \\
& f_{\left(a_{1}, a_{2}\right)}(x) \mid x \rightarrow \infty \sim a_{1} a_{2} x^{a_{1}-1}\left(1+x^{a_{1}}\right)^{-a_{2}-1} \times \frac{1+\log \left\{1-1-\left(1+x^{a_{1}}\right)^{-a_{2}}\right\}}{-\log \left\{1-\left[1-\left(1+x^{a_{1}}\right)^{-a_{2}}\right]\right\}}, \\
& h_{\left(a_{1}, a_{2}\right)}(x) \mid x \rightarrow \infty \sim a_{1} a_{2} x^{a_{1}-1}\left(1+x^{a_{1}}\right)^{-a_{2}-1}\left\{1-\left[1-\left(1+x^{a_{1}}\right)^{-a_{2}}\right]\right\}^{-1} \\
& \times \frac{1+\log \left\{1-\left[1-\left(1+x^{a_{1}}\right)^{-a_{2}}\right]\right\}}{-\log \left\{1-\left[1-\left(1+x^{a_{1}}\right)^{-a_{2}}\right]\right\}} .
\end{aligned}
$$

The effect of the parameters on tails of distribution can be evaluated by means of above equations. Figure 1 gives some plots of the BH-BXII PDF for some parameter values. Plots of the BH-BXII HRF for selected parameter values are given in Figure 2. The HRF can be decreasing $\left(a_{1}=1, a_{2}=1\right)$, unimodal $\left(a_{1}=\right.$ $\left.1.1, a_{2}=0.1\right)$ and increasing $\left(a_{1}=1.25, a_{2}=3\right.$ and $\left.a_{1}=5, a_{2}=5\right)$. 

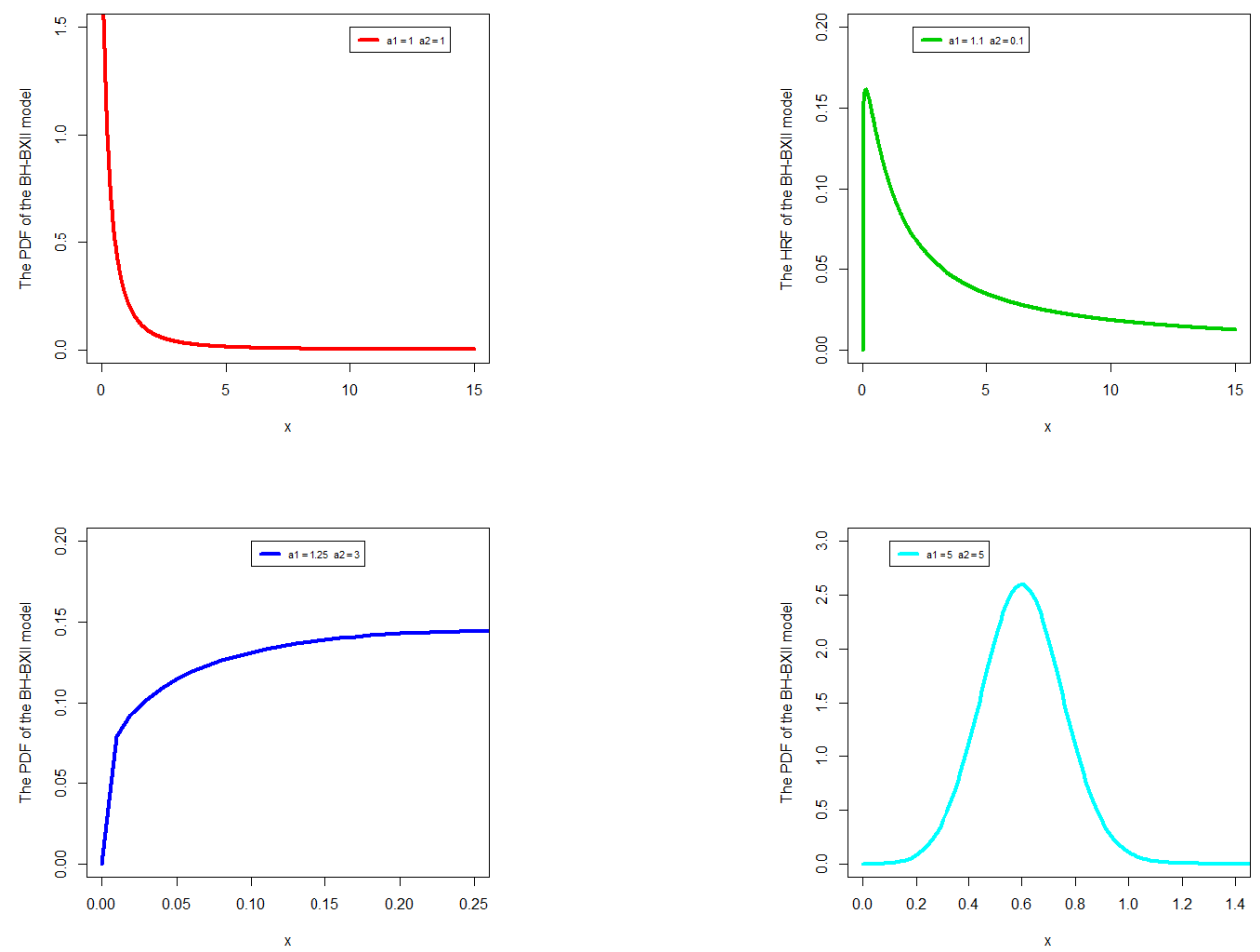

Figure 1: Plots of the BH-BXII PDF.
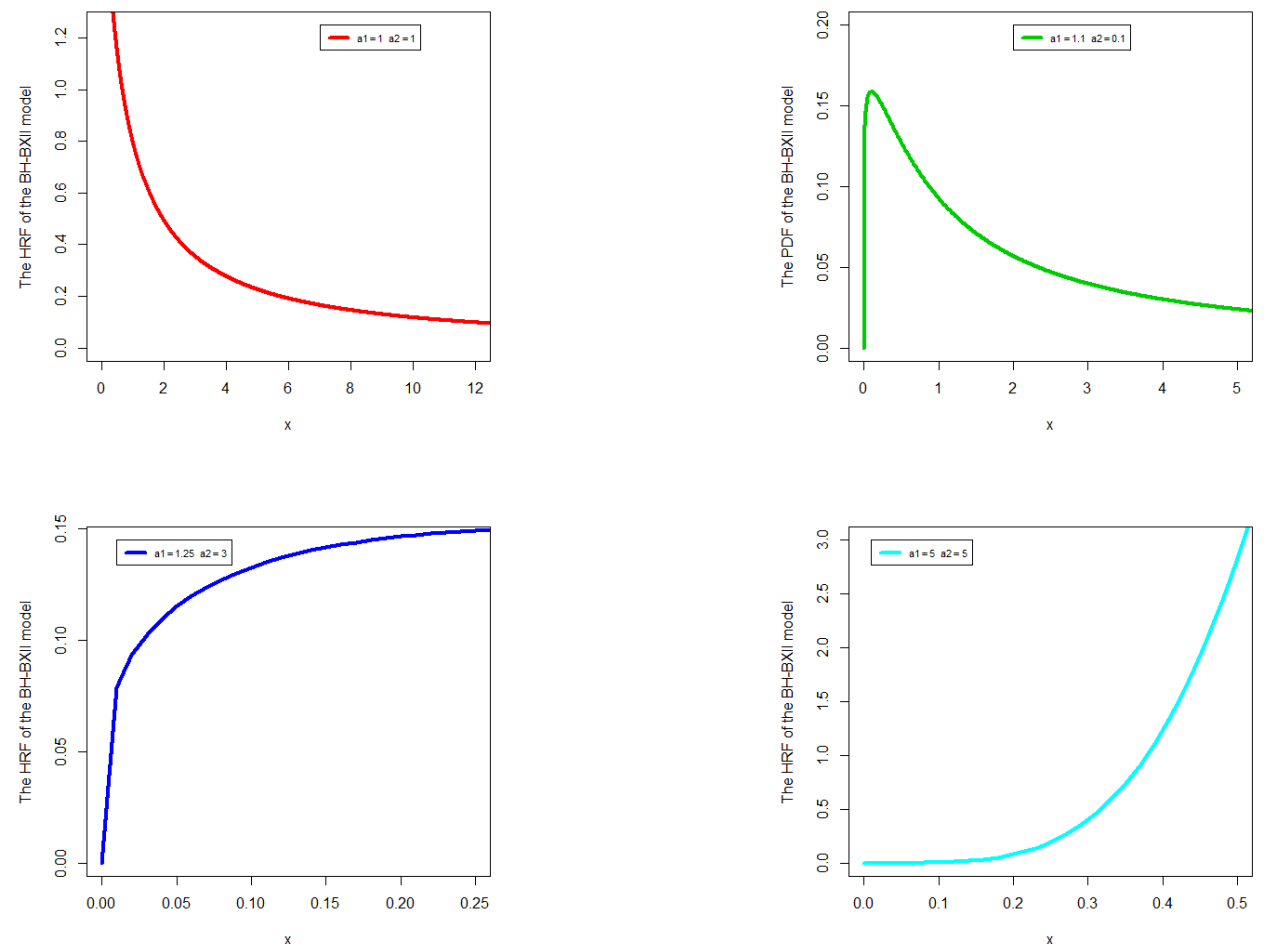

Figure 2: Plots of the BH-BXII HRF. 


\section{Properties}

\section{1. moments}

Following Yousof et al. [27], equation (1.2) can be rewritten as

$$
f_{\left(a_{1}, a_{2}\right)}(x)=\sum_{\mathbf{q}=0}^{\infty} \vartheta_{\mathbf{q}} g_{a_{1}, a_{2}(1+q)}(x),
$$

where

$$
g_{a_{1}, a_{2}(1+q)}(x)=a_{1} a_{2}(1+\mathbf{q}) x^{a_{1}-1}\left(1+x^{a_{1}}\right)^{-a_{2}(1+q)-1}
$$

is the BXII density with parameters $a_{1}$ and $a_{2}(1+\mathbf{q})$ and

$$
\vartheta_{\mathbf{q}}=\sum_{\kappa=0}^{\infty} d_{\kappa+1} \frac{(-1)^{\mathbf{q}}}{1+\mathbf{q}}(\kappa+1)\left(\begin{array}{c}
(\kappa+1)-1 \\
\mathbf{q}
\end{array}\right)
$$

where $d_{k+1}$ is defined by Yousof et al. [27] in details. Equation (5) reveals that the BH-BXII PDF is a linear combination of the BXII density with parameters $a_{1}$ and $a_{2}(1+\mathbf{q})$. Thus, some structural properties of the new model such as the ordinary and incomplete moments and generating function can be immediately obtained from well-established properties of the BXII model with parameters $a_{1}$ and $a_{2}(1+\mathbf{q})$.

The $n^{\text {th }}$ ordinary moment of $X$ is given by

$$
\mu_{n}^{\prime}=\mathbf{E}\left(X^{n}\right)=\int_{-\infty}^{\infty} x^{n} f_{\left(a_{1}, a_{2}\right)}(x) d x
$$

Then, we obtain

$$
\mu_{n}^{\prime}=\sum_{\mathbf{q}=0}^{\infty} \vartheta_{\mathbf{q}} a_{2}(1+\mathbf{q}) a_{2}\left(a_{2}(1+\mathbf{q})-\frac{n}{a_{1}}, \frac{n}{a_{1}}+1\right), \forall\left[n<a_{1} a_{2}(1+\mathbf{q})\right]
$$

Setting $n=1,2,3$, and 4 in (2.1), we have

$$
\begin{array}{r}
\mathbf{E}(X)=\mu_{1}^{\prime}=\sum_{\mathbf{q}=0}^{\infty} \vartheta_{\mathbf{q}} a_{2}(1+\mathbf{q}) a_{2}\left(a_{2}(1+\mathbf{q})-\frac{1}{a_{1}}, \frac{1}{a_{1}}+1\right), \forall\left[1<a_{1} a_{2}(1+\mathbf{q})\right], \\
\mathbf{E}\left(X^{2}\right)=\mu_{2}^{\prime}=\sum_{\mathbf{q}=0}^{\infty} \vartheta_{\mathbf{q}} a_{2}(1+\mathbf{q}) a_{2}\left(a_{2}(1+\mathbf{q})-\frac{2}{a_{1}}, \frac{2}{a_{1}}+1\right), \forall\left[2<a_{1} a_{2}(1+\mathbf{q})\right], \\
\mathbf{E}\left(X^{3}\right)=\mu_{3}^{\prime}=\sum_{\mathbf{q}=0}^{\infty} \vartheta_{\mathbf{q}} a_{2}(1+\mathbf{q}) a_{2}\left(a_{2}(1+\mathbf{q})-\frac{3}{a_{1}}, \frac{3}{a_{1}}+1\right), \forall\left[3<a_{1} a_{2}(1+\mathbf{q})\right],
\end{array}
$$

and

$$
\mathbf{E}\left(X^{4}\right)=\mu_{4}^{\prime}=\sum_{\mathbf{q}=0}^{\infty} \vartheta_{\mathbf{q}} \mathrm{a}_{2}(1+\mathbf{q}) \mathrm{B}\left(\mathrm{a}_{2}(1+\mathbf{q})-\frac{4}{\mathrm{a}_{1}}, \frac{4}{\mathrm{a}_{1}}+1\right), \forall\left[4<\mathrm{a}_{1} \mathrm{a}_{2}(1+\mathbf{q})\right]
$$

The last results can be computed numerically. The skewness and kurtosis measures can be calculated from the ordinary moments using well-known relationships. 


\subsection{Incomplete moments}

The $\mathrm{n}^{\text {th }}$ incomplete moment of $\mathrm{X}$ is defined by

$$
\mathbf{I}_{\mathfrak{n}}(\mathrm{t})=\int_{-\infty}^{t} x^{\mathrm{n}} f_{\left(\mathrm{a}_{1}, \mathrm{a}_{2}\right)}(x) \mathrm{d} x
$$

Then, we can write

$$
\mathbf{I}_{\mathfrak{n}}(\mathbf{t})=\sum_{\mathbf{q}=0}^{\infty} \vartheta_{\mathbf{q}} \mathrm{a}_{2}(1+\mathbf{q}) B\left(\mathrm{t}^{\mathrm{a}_{1}} ; \mathrm{a}_{2}(1+\mathbf{q})-\frac{\mathrm{n}}{\mathrm{a}_{1}}, \frac{\mathrm{n}}{\mathrm{a}_{1}}+1\right), \forall\left[\mathrm{n}<\mathrm{a}_{1} \mathrm{a}_{2}(1+\mathbf{q})\right]
$$

where

$$
B\left(a_{1}, a_{2}\right)=\int_{0}^{\infty} t^{a_{1}-1}(1+t)^{-\left(a_{1}+a_{2}\right)} d t
$$

and

$$
B\left(a_{3} ; a_{1}, a_{2}\right)=\int_{0}^{a_{3}} t^{a_{1}-1}(1+t)^{-\left(a_{1}+a_{2}\right)} d t
$$

are the beta and the incomplete beta functions of the second type, respectively. Setting $n=1$ in (2.2), we have

$$
\mathbf{I}_{1}(\mathbf{t})=\sum_{\mathbf{q}=0}^{\infty} \vartheta_{\mathbf{q}} \mathrm{a}_{2}(1+\mathbf{q}) B\left(t^{a_{1}} ; a_{2}(1+\mathbf{q})-\frac{1}{a_{1}}, \frac{1}{a_{1}}+1\right) \forall\left[1<a_{1} a_{2}(1+\mathbf{q})\right],
$$

which is the the first incomplete moment. There are two important applications of the $\mathbf{I}_{1}(\mathrm{t})$ related to the mean deviations about the mean, $M_{1}$, and median, $M_{2}$, and to the Bonferroni and Lorenz curves. The mean deviations about the mean $\left[M_{1}=\mathbf{E}\left(\left|X-\mu_{1}^{\prime}\right|\right)\right]$ and about the median $\left[M_{2}=\mathbf{E}(|X-M|)\right]$ of $X$ are given by $M_{1}=2 \mu_{1}^{\prime} F\left(\mu_{1}^{\prime}\right)-2 \mathbf{I}_{1}\left(\mu_{1}^{\prime}\right)$ and $M_{2}=\mu_{1}^{\prime}-2 \mathbf{I}_{1}(M)$, respectively, where $\mu_{1}^{\prime}=\mathbf{E}(X), M=$ $\mathrm{Q}(\mathrm{u})=\mathrm{F}^{-1}(\mathrm{u})$ is the median of $\mathrm{X}, \mathrm{F}\left(\mu_{1}^{\prime}\right)$ is easily calculated from (1.1) and $\mathbf{I}_{1}(\mathrm{t})$ is the first incomplete moment. The Lorenz and Bonferroni curves are important in several applied areas such as economics, reliability, demography, insurance and medicine. For a given probability $\pi>0$, they are defined by $\operatorname{Lo}(\pi)=\mathrm{m}_{1}(\mathrm{q}) / \mathrm{E}(\mathrm{X})$ and $\operatorname{Bo}(\pi)=\operatorname{Lo}(\pi) / \pi$, respectively, where $\mathrm{q}=\mathrm{Q}(\pi)=\mathrm{Q}(\pi)$ comes directly from the QF of $X$.

\subsection{Moment generating function}

The moment generating function (MGF) of $X$, say $M_{X}(t)=E[\exp (t X)]$. Paranaí ba et al. [17] provided a simple representation for the MGF of the BXII model. In a similar manner, we provide another representation for the MGF, say $M_{X}(t)$, of the BXII $\left(a_{1}, a_{2}\right)$ model. For $t<0$, we can write

$$
M(t)=a_{1} a_{2} \int_{0}^{\infty} \exp (y t) y^{a_{1}-1}\left(1+y^{a_{1}}\right)^{-a_{2}-1} d y
$$

Next, we require the Meijer G-function defined by

$$
\mathbf{G}_{p, q}^{m, n}\left(x \mid \begin{array}{l}
\left(a_{1}\right)_{1}, \ldots,\left(a_{1}\right)_{p} \\
\left(a_{2}\right)_{1}, \ldots,\left(a_{2}\right)_{q}
\end{array}\right)=\frac{1}{2 \pi i} \int_{L} \frac{\prod_{j=1}^{m} \Gamma\left(\left(a_{2}\right)_{j}+t\right) \prod_{j=1}^{n} \Gamma\left(1-\left(a_{1}\right)_{j}-t\right)}{\prod_{j=n+1}^{p} \Gamma\left(\left(a_{1}\right)_{j}+t\right) \prod_{j=m+1}^{p} \Gamma\left(1-\left(a_{2}\right)_{j}-t\right)} x^{-t} d t,
$$

where $i=\sqrt{-1}$ is the complex unit and L denotes an integration path (Gradshteyn and Ryzhik [13]). The Meijer G-function contains as particular cases many integrals with elementary and special functions (Prudnikov et al., [19]), where $m$ and $a_{2}$ are positive integers. This condition is not restrictive since every 
positive real number can be approximated by a rational number. We have the following result, which holds for $\mathrm{m}$ and $\mathrm{k}$ positive integers, $\mu>-1$ and $\mathrm{p}>0$ (Prudnikov et al., [20])

$$
\begin{aligned}
\left.\mathbf{I}\left(p, \mu, \frac{\mathrm{m}}{\mathrm{a}_{2}}, \mathrm{u}\right)\right|_{0} ^{\infty} & =\int_{0}^{\infty} \exp (-\mathrm{px}) x^{\mu}\left(1+x^{\mathrm{m} / \mathrm{a}_{2}}\right)^{\mathrm{u}} \mathrm{dx} \\
& =\delta \mathbf{G}_{\mathrm{a}_{2}+\mathrm{m}, \mathrm{a}_{2}}^{\mathrm{a}_{2} \mathrm{a}_{2}+\mathrm{m}}\left(\left(\mathrm{m}^{\mathrm{m}} \mathrm{p}^{-\mathrm{m}}\right) \mid \begin{array}{c}
\Delta(\mathrm{m},-\mu), \triangle\left(\mathrm{a}_{2}, \mathrm{u}+1\right) \\
\triangle\left(\mathrm{a}_{2}, 0\right)
\end{array}\right),
\end{aligned}
$$

where

$$
\delta=\left(a_{2}^{-u} m^{\mu+\frac{1}{2}}\right)\left[(2 \pi)^{\frac{m-1}{2}} p^{\mu+1} \Gamma(-u)\right]^{-1}
$$

and

$$
\triangle(\tau, \zeta)=\zeta / \tau,(\zeta+1) / \tau, \ldots,(\zeta+\tau) / \tau
$$

We can write (for $t<0)$

$$
M(t)=m I\left(-t, \frac{m}{a_{2}}-1, \frac{m}{a_{2}},-a_{2}-1\right) .
$$

Hence, the MGF of $X$ can be expressed as

$$
M_{X}(t)=\left.m \sum_{\mathbf{q}=0}^{\infty} \vartheta_{\mathbf{q}}\left[\mathbf{I}\left(-t,-1+\frac{m}{a_{2}(1+\mathbf{q})}, \frac{m}{a_{2}(1+\mathbf{q})},-\left[a_{2}(1+\mathbf{q})+1\right]\right)\right]\right|_{0} ^{\infty} .
$$

\subsection{Moment of residual life and reversed residual life}

The $\mathrm{n}^{\text {th }}$ moment of the residual life, denoted by

$$
m_{n}(t)=E\left[(X-t)^{n} \mid X>t\right], n=1,2, \ldots,
$$

uniquely determines $F_{\left(a_{1}, a_{2}\right)}(x)$ (see Navarro et al., 1998). The $n^{\text {th }}$ moment of the residual life of $X$ is given by

$$
m_{n}(t)=\frac{\int_{t}^{\infty}(x-t)^{n} d F_{\left(a_{1}, a_{2}\right)}(x)}{1-F_{\left(a_{1}, a_{2}\right)}(t)}
$$

Then, we can write

$$
\begin{aligned}
m_{n}(t)= & \frac{1}{1-F_{\left(a_{1}, a_{2}\right)}(t)} \sum_{i=0}^{n} \sum_{\mathbf{q}=0}^{\infty} \frac{(-1)^{n-i} n ! t^{n-i}}{i ! \Gamma(n-i+1)} \vartheta_{\mathbf{q}} a_{2}(1+\mathbf{q}) \\
& \times B\left(t^{a_{1}} ; a_{2}(1+\mathbf{q})-\frac{n}{a_{1}}, \frac{n}{a_{1}}+1\right), \forall\left[n<a_{1} a_{2}(1+\mathbf{q})\right] .
\end{aligned}
$$

Another interesting function is the mean residual life (MRL) function or the life expectation at age $x$ defined by $m_{1}(x)=E[(X-x) \mid X>x]$, which represents the expected additional life length for a unit which is alive at age $x$. The MRL of the BH-BXII distribution can be obtained by setting $n=1$ in the last equation. The $n^{\text {th }}$ moment of the reversed residual life, say $M_{n}(t)=E\left[(t-X)^{n} \mid X \leqslant t\right]$ for $t>0$ and $n=1,2, \ldots$ uniquely determines $F(x)$. Then, $M_{n}(t)$ is defined by

$$
M_{n}(t)=\frac{\int_{0}^{t}(t-x)^{n} d F_{\left(a_{1}, a_{2}\right)}(x)}{F_{\left(a_{1}, a_{2}\right)}(t)} .
$$

The $\mathrm{n}^{\text {th }}$ moment of the reversed residual life of $X$ is

$$
M_{n}(t)=\frac{1}{F(t)} \sum_{i=0}^{n} \sum_{\mathbf{q}=0}^{\infty} \frac{(-1)^{i} n !}{i !(n-i) !} \vartheta_{\mathbf{q}} a_{2}(1+\mathbf{q})
$$




$$
\times B\left(t^{a_{1}} ; a_{2}(1+q)-\frac{n}{a_{1}}, \frac{n}{a_{1}}+1\right), \forall\left[n<a_{1} a_{2}(1+q)\right] .
$$

The mean inactivity time (MIT) or mean waiting time (MWT), also called the mean reversed residual life function, say $M_{1}(t)=E[(t-X) \mid X \leqslant t]$, represents the waiting time elapsed since the failure of an item on condition that this failure had occurred in $(0, x)$. The MIT of $X$ can be obtained by setting $n=1$ in the above equation.

\section{Simple type copula based construction}

In this Section, we consider several approaches to construct the bivariate and the multivariate $\mathrm{BH}-$ BXII type distributions via copula or with straightforward bivariate CDFs form, in which we only need to consider two different BH-BXII CDFs.

\subsection{Via Morgenstern family}

First, we start with CDF for Morgenstern family of two random variables $\left(X_{1}, X_{2}\right)$ which has the following form

$$
\left.\mathrm{F}_{\lambda}\left(\mathrm{x}_{1}, \mathrm{x}_{2}\right)\right|_{(|\lambda| \leqslant 1)}=\mathrm{F}_{1}\left(\mathrm{x}_{1}\right) \mathrm{F}_{2}\left(\mathrm{x}_{2}\right)\left\{1+\lambda\left[1-\mathrm{F}_{1}\left(\mathrm{x}_{1}\right)\right]\left[1-\mathrm{F}_{2}\left(\mathrm{x}_{2}\right)\right]\right\},
$$

setting

$$
\mathrm{F}_{\left(\mathrm{a}_{1}, \mathrm{a}_{2}\right)}\left(\mathrm{x}_{1}\right)=1-\frac{1-\left[1-\left(1+x_{1}^{\mathrm{a}_{1}}\right)^{-\mathrm{a}_{2}}\right]}{1-\log \left\{1-\left[1-\left(1+x_{1}^{\mathrm{a}_{1}}\right)^{-\mathrm{a}_{2}}\right]\right\}},
$$

and

$$
\mathrm{F}_{\left(\mathrm{b}_{1}, \mathrm{~b}_{2}\right)}\left(\mathrm{x}_{2}\right)=1-\frac{1-\left[1-\left(1+\mathrm{x}_{2}^{\mathrm{b}_{1}}\right)^{-\mathrm{b}_{2}}\right]}{1-\log \left\{1-\left[1-\left(1+\mathrm{x}_{2}^{\mathrm{b}_{1}}\right)^{-\mathrm{b}_{2}}\right]\right\}^{\prime}}
$$

then we have a five dimension parameter model as

$$
\begin{aligned}
\left.\mathrm{F}_{\lambda}\left(\mathrm{x}_{1}, \mathrm{x}_{2}\right)\right|_{(|\lambda| \leqslant 1)}= & \left(1-\frac{1-\left[1-\left(1+x_{1}^{\mathrm{a}_{1}}\right)^{-\mathrm{a}_{2}}\right]}{1-\log \left\{1-\left[1-\left(1+\mathrm{x}_{1}^{\mathrm{a}_{1}}\right)^{-\mathrm{a}_{2}}\right]\right\}}\right) \\
& \times\left(1-\frac{1-\left[1-\left(1+x_{2}^{\mathrm{b}_{1}}\right)^{-\mathrm{b}_{2}}\right]}{1-\log \left\{1-\left[1-\left(1+\mathrm{x}_{2}^{\mathrm{b}_{1}}\right)^{-\mathrm{b}_{2}}\right]\right\}}\right)\left[\begin{array}{c}
1+ \\
\lambda \times\left(\frac{1-\left[1-\left(1+\mathrm{x}_{1}^{\mathrm{a}_{1}}\right)^{-\mathrm{a}_{2}}\right]}{1-\log \left\{1-\left[1-\left(1+\mathrm{x}_{1}^{\mathrm{a}_{1}}\right)^{-\mathrm{a}_{2}}\right]\right\}}\right) \\
\times\left(\frac{1-\left[1-\left(1+\mathrm{x}_{2}^{\mathrm{b}_{1}}\right)^{-\mathrm{b}_{2}}\right]}{1-\log \left\{1-\left[1-\left(1+\mathrm{x}_{2}^{\mathrm{b}_{1}}\right)^{-\mathrm{b}_{2}}\right]\right\}}\right)
\end{array}\right.
\end{aligned}
$$

\subsection{Via clayton copula}

\subsubsection{The bivariate extension}

The bivariate extension via clayton copula can be considered as a weighted version of the clayton copula, which is of the form

$$
\mathrm{C}(\mathrm{u}, \boldsymbol{v})=\left[\mathrm{u}^{-\left(\delta_{1}+\delta_{2}\right)}+v^{-\left(\delta_{1}+\delta_{2}\right)}-1\right]^{-\frac{1}{\delta_{1}+\delta_{2}}}
$$


This is indeed a valid copula. Next, let us assume that $X \sim \operatorname{BH}-B X I I\left(a_{1}, a_{2}\right)$ and $Y \sim \operatorname{BH}-B X I I\left(\left(b_{1}, b_{2}\right)\right.$. Then, setting

and

$$
u=1-\frac{1-\left[1-\left(1+\chi^{\mathbf{a}_{1}}\right)^{-\mathbf{a}_{2}}\right]}{1-\log \left\{1-\left[1-\left(1+x^{\mathbf{a}_{1}}\right)^{-\mathbf{a}_{2}}\right]\right\}}
$$

$$
v=1-\frac{1-\left[1-\left(1+y^{b_{1}}\right)^{-b_{2}}\right]}{1-\log \left\{1-\left[1-\left(1+y^{b_{1}}\right)^{-b_{2}}\right]\right\}^{\prime}}
$$

the associated CDF bivariate BH-BXII type distribution will be

$$
\mathrm{H}(x, y)=\left[\begin{array}{c}
\left(1-\frac{1-\left[1-\left(1+x^{a_{1}}\right)^{-a_{2}}\right]}{1-\log \left\{1-\left[1-\left(1+x^{\left.\left.\left.a_{1}\right)^{-a_{2}}\right]\right\}}\right.\right.\right.}\right) \\
+\left(1-\frac{1-\left[1-\left(1+y^{b_{1}}\right)^{-b_{2}}\right]}{1-\log \left\{1-\left[1-\left(1+y^{\left.\left.\left.b_{1}\right)^{-b_{2}}\right]\right\}}\right.\right.\right.}\right) \\
-1
\end{array}\right]^{-\frac{1}{\delta_{1}+\delta_{2}}} .
$$

Note: Depending on the specific baseline CDF, one may construct various bivariate BH-BXII type model in which $\left(\delta_{1}+\delta_{2}\right) \geqslant 0$.

\subsubsection{The Multivariate extension}

A straightforward d-dimensional extension IRom the above will be

$$
H\left(x_{1}, x_{2}, \ldots, x_{d}\right)=\left[\sum_{i=1}^{d}\left(1-\frac{1-\left[1-\left(1+x_{i}^{a_{1}}\right)^{-a_{i}}\right]}{1-\log \left\{1-\left[1-\left(1+x_{i}^{a_{i}}\right)^{-a_{i}}\right]\right\}}\right)^{-\left(\delta_{1}+\delta_{2}\right)}+1-d\right]^{-1 /\left(\delta_{1}+\delta_{2}\right)} .
$$

Further future works could be be allocated for studying the bivariate and the multivariate extensions of the BH-BXII model.

\section{Estimation}

Consider the following classical estimation methods:

1. Maximum likelihood estimation (MLE).

2. Anderson Darling estimation (ADE).

3. Right Tail-Anderson Darling estimation (R.T. ADE).

4. Left Tail-Anderson Darling estimation (L.T. ADE).

\subsection{The maximum likelihood method}

Several approaches for parameter estimation were proposed in the literature but the maximum likelihood method is the most commonly employed. The maximum likelihood estimators (MLEs) enjoy desirable properties and can be used for constructing confidence intervals and regions and also in test statistics. The normal approximation for these estimators in large samples can be easily handled either analytically or numerically. So, we consider the estimation of the unknown parameters of this model from complete samples only by maximum likelihood. Let $x_{1}, \ldots, x_{n}$ be a random sample from the BH-BXII distribution with parameters $a_{1}$ and $a_{2}$. Let $\Psi=\left(a_{1}, a_{2}\right)^{\top}$ be the $2 \times 1$ parameter vector. For determining the MLE of $\Psi$, we have the log-likelihood function

$$
\ell(\Psi)=n \log a_{1}+n \log a_{2}+\left(a_{1}-1\right) \sum_{i=1}^{n} \log x_{i}-\left(a_{2}+1\right) \sum_{i=1}^{n} \log \left(1+x_{i}^{a_{1}}\right)
$$




$$
\begin{aligned}
& -2 \sum_{i=1}^{n} \log \left(1-\log \left\{1-\left[1-\left(1+x_{i}^{a_{1}}\right)^{-a_{2}}\right]\right\}\right) \\
& +\sum_{i=1}^{n} \log \left\{\left[1-\log \left\{1-\left[1-\left(1+x_{i}^{a_{1}}\right)^{-a_{2}}\right]\right\}\right]+1\right\} .
\end{aligned}
$$

The components of the score vector, $\mathbf{U}(\Psi)=\frac{\partial \ell(\Psi)}{\partial \Psi}=\left(\frac{\partial \ell(\Psi)}{\partial a_{1}}, \frac{\partial \ell(\Psi)}{\partial a_{2}}\right)^{\top}$ are available if needed. Setting the nonlinear system of equations $\mathrm{U}_{\mathrm{a}_{1}}=\mathrm{U}_{\mathrm{a}_{2}}=0$ and solving them simultaneously yields the MLE $\widehat{\Psi}=\left(\widehat{a_{1}}, \widehat{a_{2}}\right)^{\top}$. To solve these equations, it is usually more convenient to use nonlinear optimization methods such as the quasi-Newton algorithm to numerically maximize $\ell$. For interval estimation of the parameters, we obtain the $2 \times 2$ observed information matrix $J(\Psi)=\left\{\frac{\partial^{2} \ell(\Psi)}{\partial \mathbf{q} \partial s}\right\}$ (for $\mathbf{q}, s=a_{1}, a_{2}$ ), whose elements can be computed numerically. Under standard regularity conditions when $n \rightarrow \infty$, the distribution of $\widehat{\Psi}$ can be approximated by a multivariate normal $\mathrm{N}_{2}\left(0, \mathrm{~J}(\widehat{\Psi})^{-1}\right)$ distribution to construct approximate confidence intervals for the parameters. Here, $\mathrm{J}(\widehat{\Psi})$ is the total observed information matrix evaluated at $\widehat{\Psi}$. The method of the re-sampling bootstrap can be used for correcting the biases of the MLEs of the model parameters. Good interval estimates may also be obtained using the bootstrap percentile method.

\subsection{The $A D E$}

The $\mathrm{ADE}$ of $\widehat{\mathrm{a}_{1}}(\mathrm{ADE})$ and $\widehat{\mathrm{a}_{2}}(\mathrm{ADE})$ are obtained by minimizing the function

$$
\operatorname{ADE}\left(a_{1}, a_{2}\right)=-n-n^{-1} \sum_{i=1}^{n}(2 i-1)\left[\begin{array}{c}
\log \left(1-\frac{1-\left[1-\left(1+x_{[i: n]}^{a_{1}}\right)^{-a_{2}}\right]}{1-\log \left\{1-\left[1-\left(1+x_{[i: n]}^{a_{1}}\right)^{-a_{2}}\right]\right\}}\right) \\
+\log \left(\frac{1-\left[1-\left(1+x_{[-i+1+n: n]}^{a_{1}}\right)^{-a_{2}}\right]}{1-\log \left\{1-\left[1-\left(1+x_{[-i+1+n: n]}^{a_{1}}\right)^{-a_{2}}\right]\right\}}\right)
\end{array}\right] .
$$

The parameter estimates of $\widehat{a_{1}}(\mathrm{ADE})$ and $\widehat{a_{2}}(\mathrm{ADE})$ follow by solving the nonlinear equations

$$
\frac{\partial}{\partial a_{1}}\left[\operatorname{ADE}\left(a_{1}, a_{2}\right)\right]=0 \text { and } \frac{\partial}{\partial a_{2}}\left[\operatorname{ADE}\left(a_{1}, a_{2}\right)\right]=0 .
$$

\subsection{The R.T. $A D E$}

The R.T. ADE of $\widehat{a_{1}}$ (R.T. ADE) and $\widehat{a_{2}}$ (R.T. ADE) are obtained by minimizing

$$
\begin{aligned}
\text { R.T. } \operatorname{ADE}\left(\mathrm{a}_{1}, \mathrm{a}_{2}\right)= & \frac{1}{2} n-2 \sum_{i=1}^{n}\left(1-\frac{1-\left[1-\left(1+x_{[i: n]}^{a_{1}}\right)^{-a_{2}}\right]}{1-\log \left\{1-\left[1-\left(1+x_{[i: n]}^{a_{1}}\right)^{-a_{2}}\right]\right\}}\right) \\
& -\frac{1}{n} \sum_{i=1}^{n}(2 i-1)\left[\log \left(\frac{1-\left[1-\left(1+x_{[-i+1+n: n]}^{a_{1}}\right)^{-a_{2}}\right]}{1-\log \left\{1-\left[1-\left(1+x_{[-i+1+n: n]}^{a_{1}}\right)^{-a_{2}}\right]\right\}}\right)\right] .
\end{aligned}
$$

The parameter estimates of $\widehat{a_{1}}$ (R.T. ADE) and $\widehat{a_{2}}$ (R.T. ADE) follow by solving the nonlinear equations

$$
\frac{\partial}{\partial a_{1}}\left[\text { R.T. } \operatorname{ADE}\left(a_{1}, a_{2}\right)\right]=0 \quad \text { and } \quad \frac{\partial}{\partial a_{2}}\left[\text { R.T. } \operatorname{ADE}\left(a_{1}, a_{2}\right)\right]=0 \text {. }
$$


4.4. The L.T. ADE

The L.T. ADE of $\widehat{a_{1}}$ (L.T. ADE) and $\widehat{a_{2}}$ (L.T. ADE) are obtained by minimizing

$$
\begin{aligned}
\text { L.T. } \operatorname{ADE}\left(\mathrm{a}_{1}, \mathrm{a}_{2}\right)= & -\frac{3}{2} n+2 \sum_{i=1}^{n}\left(1-\frac{1-\left[1-\left(1+x_{[i: \mathrm{n}]}^{\mathrm{a}_{1}}\right)^{-\mathrm{a}_{2}}\right]}{1-\log \left\{1-\left[1-\left(1+x_{[i: \mathrm{n}]}^{a_{1}}\right)^{-a_{2}}\right]\right\}}\right) \\
& -\frac{1}{n} \sum_{i=1}^{n}(2 i-1) \log \left(1-\frac{\left\{1-\left[1-\left(1+x_{[i: \mathrm{n}]}^{\mathrm{a}_{1}}\right)^{-\mathrm{a}_{2}}\right]\right\}}{1-\log \left\{1-\left[1-\left(1+x_{[i: \mathrm{n}]}^{a_{1}}\right)^{-a_{2}}\right]\right\}}\right) .
\end{aligned}
$$

The parameter estimates of $\widehat{a_{1}}$ (L.T. ADE) and $\widehat{a_{2}}$ (L.T. ADE) follow by solving the nonlinear equations

$$
\frac{\partial}{\partial a_{1}}\left[\text { L.T. } \operatorname{ADE}\left(a_{1}, a_{2}\right)\right]=0 \quad \text { and } \quad \frac{\partial}{\partial a_{2}}\left[\text { L.T. } \operatorname{ADE}\left(a_{1}, a_{2}\right)\right]=0 \text {. }
$$

\section{Comparing methods}

\subsection{Using simulated data for survival times}

For comparing classical methods, an application to real data set is introduced. We consider the Cramér-Von Mises $\left(\mathrm{CVM}^{*}\right)$ and Anderson Darling statistics. In this section, we will introduce and analyze a new medical data set. This simulated data set gives the survival times (in days) of 73 patients suffering from acute bone cancer. The data set are: $0.09,0.76,1.81,1.10,3.72,0.72,2.49,1.00,0.53,0.66,31.61,0.60$, $0.20,1.61,1.88,0.70,1.36,0.43,3.16,1.57,4.93,11.07,1.63,1.39,4.54,3.12,86.01,1.92,0.92,4.04,1.16,2.26$, $0.20,0.94,1.82,3.99,1.46,2.75,1.38,2.76,1.86,2.68,1.76,0.67,1.29,1.56,2.83,0.71,1.48,2.41,0.66,0.65$, $2.36,1.29,13.75,0.67,3.70,0.76,3.63,0.68,2.65,0.95,2.30,2.57,0.61,3.93,1.56,1.29,9.94,1.67,1.42,4.18$, 1.37. From Table 1, the MLE method is the best method with $a_{1}=2.579, a_{2}=0.293, C V M^{*}=0.10446$, and $\mathrm{AD}^{*}=0.66184$, however all other methods performed well.

Table 1: Comparing methods via a real data.

\begin{tabular}{|c|c|c|c|c|}
\hline Method & $\widehat{\mathrm{a}_{1}}$ & $\widehat{\mathrm{a}_{2}}$ & $\mathrm{CVM}^{*}$ & $\mathrm{AD}^{*}$ \\
\hline MLE & $\mathbf{2 . 5 7 9}$ & $\mathbf{0 . 2 9 3}$ & $\mathbf{0 . 1 0 4 4 6}$ & $\mathbf{0 . 6 6 1 8 4}$ \\
ADE & 2.773 & 0.267 & 0.11406 & 0.70675 \\
RLADE & 3.242 & 0.239 & 0.13847 & 0.82244 \\
LEADE & 2.595 & 0.266 & 0.10677 & 0.67468 \\
\hline
\end{tabular}

\subsection{Using a simulation experiments}

A numerical simulation is performed in to compare the classical estimation methods. The simulation study is based on $\mathrm{N}=1000$ generated data sets from the BH-BXII version where $n=50,100,300,500$ and 1000 and

$$
\begin{array}{lll} 
& \mathrm{a}_{1} & \mathrm{a}_{2} \\
\text { I } & 0.8 & 0.5 \\
\text { II } & 1.2 & 3.0 \\
\text { III } & 0.9 & 0.9
\end{array}
$$

The estimates are compared in terms of their

1. bias $\left(\operatorname{BIAS}_{(\underline{\varphi})}\right)$;

2. root mean-standard error $\left(\operatorname{RMSE}_{(\underline{\varphi})}\right)$; 
3. the mean of the absolute difference between the theoretical and the estimates $\left[D_{(a b s)}\right]$ and

4. the maximum absolute difference between the true parameters and estimates $\left[D_{(\max )}\right]$,

where

$$
\begin{array}{rlrl}
\operatorname{BIAS}_{\left(a_{1}\right)} & =\frac{1}{B} \sum_{i=1}^{B}\left(\widehat{\left(a_{1}\right)_{i}}-a_{1}\right), & \operatorname{BIAS}_{\left(a_{2}\right)}=\frac{1}{B} \sum_{i=1}^{B}\left(\widehat{\left(a_{2}\right)_{i}}-a_{2}\right), \\
\operatorname{RMSE}_{\left(a_{1}\right)}=\left\{\frac{1}{B} \sum_{i=1}^{B}\left(\widehat{\left(a_{1}\right)_{i}}-a_{1}\right)^{2}\right\}^{\frac{1}{2}}, & \operatorname{RMSE}_{\left(a_{2}\right)}=\left\{\frac{1}{B} \sum_{i=1}^{B}\left[\widehat{\left(a_{2}\right)_{i}}-a_{2}\right]^{2}\right\}^{\frac{1}{2}} \\
D_{(a b s)} & =\frac{1}{n B} \sum_{i=1}^{B} \sum_{j=1}^{n}\left|F_{\left(a_{1}, a_{2}\right)}\left(x_{i j}\right)-F_{\left(\widehat{a_{1}}, \widehat{a_{2}}\right)}\left(t_{i j}\right)\right| &
\end{array}
$$

and

$$
D_{(\max )}=\frac{1}{B} \sum_{i=1}^{B} \max _{j}\left|F_{\left(a_{1}, a_{2}\right)}\left(x_{i j}\right)-F_{\left(\widehat{a_{1}}, \widehat{a_{2}}\right)}\left(x_{i j}\right)\right| .
$$

From Tables 2, 3, and 4 we note that:

1. The $\operatorname{BIAS}_{(\underline{\varphi})}$ tend to zero when $\mathrm{n}$ increases which means that all estimators are non-biased.

2. The $\operatorname{RMSE}_{(\varphi)}$ tend to zero when $\mathrm{n}$ increases which means incidence of consistency property.

Table 2: Simulation results for parameters $a=0.8$ and $b=0.5$.

\begin{tabular}{|l|c|c|c|c|c|c|c|}
\hline & $\mathrm{n}$ & $\mathrm{BIAS}_{\left(\mathrm{a}_{1}\right)}$ & $\mathrm{BIAS}_{\left(\mathrm{a}_{2}\right)}$ & $\mathrm{RMSE}_{\left(a_{1}\right)}$ & $\mathrm{RMSE}_{\left(\mathrm{a}_{2}\right)}$ & $\mathrm{D}_{(\mathrm{abs})}$ & $\mathrm{D}_{(\mathrm{max})}$ \\
\hline MLE & 50 & 0.00869 & 0.00677 & 0.10446 & 0.08247 & 0.00345 & 0.00648 \\
ADE & & -0.02202 & 0.00975 & 0.10408 & 0.08842 & 0.00466 & 0.00943 \\
R.T. ADE & & -0.00447 & 0.00089 & 0.14462 & 0.08343 & 0.00097 & 0.00149 \\
L.T. ADE & & 0.00222 & 0.01421 & 0.13121 & 0.09799 & 0.00652 & 0.00982 \\
\hline MLE & 100 & 0.00867 & 0.00537 & 0.07140 & 0.05714 & 0.00292 & 0.00561 \\
ADE & & -0.01117 & 0.00276 & 0.07345 & 0.06048 & 0.00198 & 0.00393 \\
R.T. ADE & & -0.00206 & 0.00210 & 0.10327 & 0.05842 & 0.00077 & 0.00145 \\
L.T. ADE & & 0.00122 & 0.00464 & 0.09014 & 0.06664 & 0.00215 & 0.00334 \\
\hline MLE & \multirow{3}{*}{0} & 0.00184 & 0.00183 & 0.04089 & 0.03219 & 0.00089 & 0.00164 \\
ADE & & -0.00358 & -0.00062 & 0.04223 & 0.03415 & 0.00075 & 0.00136 \\
R.T. ADE & & 0.00164 & -0.00040 & 0.05525 & 0.03265 & 0.00044 & 0.00081 \\
L.T. ADE & & -0.00019 & 0.00284 & 0.05539 & 0.04037 & 0.00131 & 0.00188 \\
\hline MLE & 500 & 0.00231 & 0.00015 & 0.03128 & 0.02426 & 0.00044 & 0.00073 \\
ADE & & -0.00123 & 0.00050 & 0.03422 & 0.02699 & 0.00025 & 0.00051 \\
R.T. ADE & & -0.00119 & 0.00025 & 0.04513 & 0.02565 & 0.00033 & 0.00060 \\
L.T. ADE & & 0.00310 & -0.00068 & 0.04062 & 0.02970 & 0.00054 & 0.00105 \\
\hline MLE & 1000 & 0.00032 & -0.00007 & 0.02241 & 0.01750 & 0.00006 & 0.00011 \\
ADE & & -0.00089 & -0.00032 & 0.02294 & 0.01821 & 0.00023 & 0.00044 \\
R.T. ADE & & 0.00024 & -0.00021 & 0.03053 & 0.01748 & 0.00025 & 0.00045 \\
L.T. ADE & & -0.00008 & 0.00032 & 0.02888 & 0.02119 & 0.00015 & 0.00021 \\
\hline
\end{tabular}


Table 3: Simulation results for parameters $a=1.2$ and $b=3$.

\begin{tabular}{|l|c|c|c|c|c|c|c|}
\hline & $\mathrm{n}$ & $\mathrm{BIAS}_{\left(\mathrm{a}_{1}\right)}$ & $\mathrm{BIAS}_{\left(\mathrm{a}_{2}\right)}$ & $\mathrm{RMSE}_{\left(\mathrm{a}_{1}\right)}$ & $\mathrm{RMSE}_{\left(\mathrm{a}_{2}\right)}$ & $\mathrm{D}_{(\mathrm{abs})}$ & $\mathrm{D}_{(\max )}$ \\
\hline MLE & 50 & 0.00814 & 0.05020 & 0.10417 & 0.48466 & 0.00151 & 0.00308 \\
ADE & & 0.00502 & 0.03497 & 0.10713 & 0.52174 & 0.00113 & 0.00228 \\
R.T. ADE & & 0.00762 & 0.05372 & 0.12455 & 0.50770 & 0.00328 & 0.00504 \\
L.T. ADE & & -0.00146 & 0.10562 & 0.10328 & 0.63565 & 0.00849 & 0.01231 \\
\hline MLE & 100 & 0.00059 & 0.03888 & 0.07190 & 0.34207 & 0.00276 & 0.00409 \\
ADE & & 0.00174 & 0.02493 & 0.07999 & 0.38018 & 0.00131 & 0.00213 \\
R.T. ADE & & 0.00277 & 0.00487 & 0.08798 & 0.34528 & 0.00226 & 0.00372 \\
L.T. ADE & & -0.00144 & 0.06088 & 0.07647 & 0.44045 & 0.00513 & 0.00741 \\
\hline MLE & \multirow{3}{*}{300} & 0.00316 & 0.00560 & 0.04108 & 0.19746 & 0.001044 & 0.00168 \\
ADE & & 0.00139 & 0.00719 & 0.04380 & 0.20371 & 0.00072 & 0.00103 \\
R.T. ADE & & 0.00232 & -0.00048 & 0.05178 & 0.199801 & 0.00099 & 0.00156 \\
L.T. ADE & & 0.00065 & 0.01777 & 0.04233 & 0.24145 & 0.00151 & 0.00218 \\
\hline MLE & 500 & 0.00063 & 0.00496 & 0.03172 & 0.14853 & 0.00018 & 0.00034 \\
ADE & & -0.00049 & 0.00431 & 0.03431 & 0.15807 & 0.00022 & 0.00040 \\
R.T. ADE & & 0.00057 & 0.00521 & 0.03906 & 0.15226 & 0.00025 & 0.00042 \\
L.T. ADE & & -0.00043 & 0.00850 & 0.03226 & 0.18024 & 0.00061 & 0.00090 \\
\hline MLE & 1000 & 0.00025 & 0.00259 & 0.02323 & 0.10757 & 0.00011 & 0.00020 \\
ADE & & 0.00046 & 0.00096 & 0.02511 & 0.11771 & 0.00009 & 0.00017 \\
R.T. ADE & & 0.00046 & 0.00119 & 0.02887 & 0.11174 & 0.00012 & 0.00021 \\
L.T. ADE & & 0.00012 & 0.00172 & 0.02356 & 0.13132 & 0.00012 & 0.00021 \\
\hline
\end{tabular}

Table 4: Simulation results for parameters $a=0.9$ and $b=0.9$.

\begin{tabular}{|l|c|c|c|c|c|c|c|}
\hline & $\mathrm{n}$ & $\mathrm{BIAS}_{\left(a_{1}\right)}$ & $\mathrm{BIAS}_{\left(\mathrm{a}_{2}\right)}$ & $\mathrm{RMSE}_{\left(\mathrm{a}_{1}\right)}$ & $\mathrm{RMSE}_{\left(\mathrm{a}_{2}\right)}$ & $\mathrm{D}_{(\mathrm{abs})}$ & $\mathrm{D}_{(\mathrm{max})}$ \\
\hline MLE & 50 & 0.01096 & 0.01219 & 0.11062 & 0.14844 & 0.00260 & 0.00515 \\
ADE & & -0.00686 & 0.00634 & 0.12437 & 0.15630 & 0.00249 & 0.00415 \\
R.T. ADE & & -0.01737 & 0.00798 & 0.12446 & 0.14560 & 0.00451 & 0.00836 \\
L.T. ADE & & 0.00490 & 0.03069 & 0.14322 & 0.19095 & 0.00711 & 0.01112 \\
\hline MLE & 100 & 0.00930 & 0.00967 & 0.07431 & 0.10286 & 0.00211 & 0.00417 \\
ADE & & -0.00065 & 0.00524 & 0.08447 & 0.10809 & 0.00143 & 0.00203 \\
R.T. ADE & & -0.01184 & 0.00647 & 0.08508 & 0.10413 & 0.00328 & 0.00596 \\
L.T. ADE & & -0.00056 & 0.01782 & 0.09981 & 0.13330 & 0.00459 & 0.00666 \\
\hline MLE & \multirow{3}{*}{00} & 0.00163 & 0.00330 & 0.04319 & 0.05794 & 0.00067 & 0.00127 \\
ADE & & $0-0.00159$ & 0.00297 & 0.05059 & 0.06282 & 0.00096 & 0.00142 \\
R.T. ADE & & -0.00292 & 0.00207 & 0.04841 & 0.05808 & 0.00091 & 0.00159 \\
L.T. ADE & & 0.00670 & 0.00497 & 0.05485 & 0.07225 & 0.00119 & 0.00183 \\
\hline MLE & 500 & 0.00284 & 0.00027 & 0.03225 & 0.04366 & 0.00053 & 0.00098 \\
ADE & & 0.00138 & -0.00097 & 0.03689 & 0.04665 & 0.00043 & 0.00075 \\
R.T. ADE & & -0.00280 & 0.00113 & 0.03785 & 0.04793 & 0.00069 & 0.00129 \\
L.T. ADE & & -0.00040 & 0.00336 & 0.04267 & 0.05497 & 0.00091 & 0.00130 \\
\hline MLE & 1000 & 0.00045 & -0.00012 & 0.02319 & 0.03150 & 0.00010 & 0.00019 \\
ADE & & -0.000003 & -0.00009 & 0.02662 & 0.03363 & 0.00002 & 0.00003 \\
R.T. ADE & & -0.00119 & -0.00095 & 0.02703 & 0.03258 & 0.00024 & 0.00045 \\
L.T. ADE & & 0.00024 & 0.00092 & 0.03035 & 0.03907 & 0.00021 & 0.00034 \\
\hline
\end{tabular}




\section{Comparing models via simulated acute bone cancer data}

In this section, we will provide an application to illustrate the importance and potentiality of the BH-BXII against other competitive models. Table 5 gives all competitive models used in this comparison.

Table 5: The competitive models.

\begin{tabular}{|c|l|l|}
\hline Model & CDF & Author \\
\hline $\begin{array}{c}\text { Poisson Rayleigh-BXII } \\
\text { (PR-BXII) }\end{array}$ & $\frac{1-\exp \left[-\lambda\left(1-\exp \left\{-\left[-1+\left(x^{\left.\left.\left.\left.\left.a_{1}+1\right)^{a_{2}}\right]^{2}\right\}\right)\right]}\right.\right.\right.\right.\right.}{-\exp (-\lambda)+1}$ & Ibrahim [15] \\
\hline $\begin{array}{c}\text { Extended Poisson-BXII } \\
\text { (EP-BXII) }\end{array}$ & $\frac{1-\exp \left[-\lambda\left(1-\exp \left\{-\left[\left(1+x^{a_{1}}\right)^{a_{2}}-1\right]^{2}\right\}\right)^{\theta}\right]}{-\exp (-\lambda)+1}$ & Abdelkhalek [1] \\
\hline $\begin{array}{c}\text { Nadarajah-Haghighi-BXII } \\
\text { (NH-BXII) }\end{array}$ & $1-\exp \left\{1-\left[1+\lambda \frac{1-\left(1+x^{a_{1}}\right)^{-a_{2}}}{\left(1+x^{a_{1}}\right)^{-a_{2}}}\right]^{\theta}\right\}$ & $\begin{array}{l}\text { New based on } \\
\text { Nascimento et al., [16] }\end{array}$ \\
\hline $\begin{array}{c}\text { Extended Weibull BXII } \\
\text { (EW-BXII) }\end{array}$ & $1-\exp \left\{-\left[\left(1+x^{a_{1}}\right)^{\theta a_{2}}-1\right]^{\lambda}\right\}$ & Aboray and Butt [2] \\
\hline $\begin{array}{c}\text { BXII-BXII } \\
\text { (BXII-BXII) }\end{array}$ & $1-\left\{\left[\left(1+x^{\left.\left.\left.a_{1}\right)^{a_{2}}-1\right]^{\lambda}+1\right\}^{-\theta}}\right.\right.\right.$ & $\begin{array}{l}\text { New based on } \\
\text { Cordeiro et al., [10] }\end{array}$ \\
\hline $\begin{array}{c}\text { Weibull Generalized-BXII } \\
\text { (WG-BXII) }\end{array}$ & $1-\exp \left\{-\left[\left(1+c^{-1} x^{a_{1}}\right)^{\theta a_{2}}-1\right]^{\lambda}\right\}$ & Elbiely and Yousof [11] \\
\hline
\end{tabular}

The total time test (TTT) plot is an important graphical tool to verify whether the data can be applied to a specific distribution or not, the empirical version of the TTT plot is given by plotting

$$
\mathrm{T}(\mathbf{r} / \mathrm{n})=\left[\sum_{i=1}^{\mathbf{r}} y_{i: n}+(\mathbf{n}-\mathbf{r}) y_{r: n}\right] \div \sum_{i=1}^{n} y_{i: n}
$$

against $\mathbf{r} / n$, where $\mathbf{r}=1, \ldots, n$ and $y_{i: n}(i=1, \ldots, n)$ are the order statistics of the sample. The TTT plots the new data sets presented in Figure 3. This plot indicates that the empirical HRFs of this data sets is upside down (unimodal).

In order to compare the fitted models, we consider the following goodness-of-fit statistics: the Akaike Information Criterion (AIC), Bayesian IC (BIC), Hannan-Quinn IC (HQIC), Consistent AIC (CAIC), where

$$
\begin{aligned}
\mathrm{AIC} & =2[-\ell(\widehat{\Upsilon})+k], & \mathrm{BIC} & =2\left[-\ell(\widehat{\Upsilon})+\frac{1}{2} \mathrm{k} \log (\mathrm{n})\right], \\
\mathrm{HQIC} & =2\{-\ell(\widehat{\Upsilon})+k \log [\log (n)]\}, & \mathrm{CAIC} & =2\left[-\ell(\widehat{\Upsilon})+\frac{k n}{n-k-1}\right],
\end{aligned}
$$

where $k$ is the number of parameters, $n$ is the sample size, $-2 \ell(\widehat{r})$ is the maximized log-likelihood. Generally, the smaller these statistics are, the better fit. Table 6 gives the MLEs and standard errors (SEs) for the survival times data. Table 7 gives the values of AIC, BIC, CAIC and HQIC for the survival times data. Figure 3 gives estimated PDF, CDF, HRF and Kaplan-Meier survival plot for the survival times data. Figure 4 gives the P-P plot for new model and the competitive models.

Based on the values in Table 7 the BH-BXII provides adequate fits as compared to PR-BXII, NH-BXII, EW-BXII, BXII-BXII, WG-BXII with smallest values of AIC, BIC, HQIC, CAIC. Based on Figure 4, the new version of BXII gives adequate fits. 


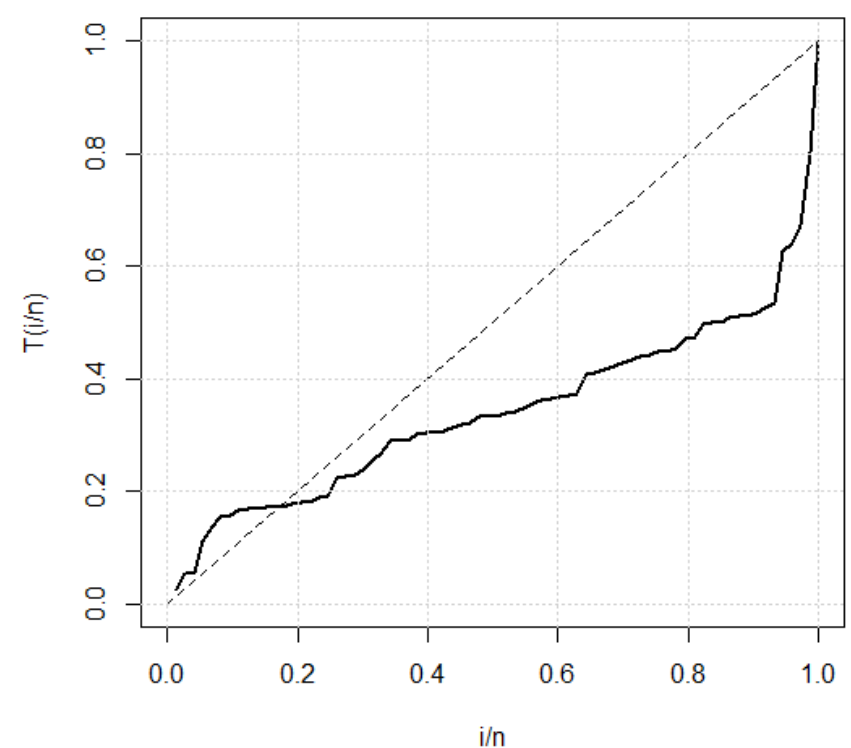

Figure 3: TTT plot for the survival times data.

Table 6: MLEs and SEs for the survival times data.

\begin{tabular}{|c|c|c|c|c|c|}
\hline Model & \multicolumn{5}{|c|}{ Estimates } \\
\hline BH-BXII $\left(a_{1}, a_{2}\right)$ & 2.5788 & 0.2934 & & & \\
& $(0.3364)$ & $(0.0475)$ & & & \\
\hline PR-BXII $\left(\lambda, a_{1}, a_{2}\right)$ & 6.3399 & 0.8766 & 0.3026 & & \\
& $(1.5272)$ & $(0.1045)$ & $(0.0421)$ & & \\
\hline EP-BXII $\left(\lambda, \theta, a_{1}, a_{2}\right)$ & -8.7894 & 36.2752 & 0.0818 & 1.7432 & \\
& $(6.9357)$ & $(50.0761)$ & $(0.0189)$ & $(0.1032)$ & \\
\hline NH-BXII $\left(\lambda, \theta, a_{1}, a_{2}\right)$ & 7.7052 & 19.0713 & 1.8018 & 0.0024 & \\
& $(0.0000)$ & $(0.000)$ & $(0.2685)$ & $(0.0004)$ & \\
\hline EW-BXII $\left(\lambda, \theta, a_{1}, a_{2}\right)$ & 0.5513 & 1.6976 & 3.9999 & $(0.12233)$ & \\
& $(0.0905)$ & $(0.0000)$ & $(0.9579)$ & $(0.0000)$ & \\
\hline BXII-BXII $\left(\lambda, \theta, a_{1}, a_{2}\right)$ & 1.6733 & 0.8148 & 1.3705 & 0.7411 & \\
& $(2.1604)$ & $(0.6809)$ & $(1.8561)$ & $(0.6114)$ & \\
\hline WG-BXII $\left(\lambda, \theta, a_{1}, a_{2}, c\right)$ & $(0.3129)$ & $(1.3472)$ & 5.9651 & 0.1938 & 1.4978 \\
& 0.2061515 & $(0.0000)$ & $(3.4677)$ & $(0.0000)$ & $(0.4598)$ \\
\hline
\end{tabular}

Table 7: AIC, BIC, CAIC, and HQIC values for the survival times data.

\begin{tabular}{|c|c|}
\hline Model & AIC, CAIC, BIC, HQIC \\
\hline BH-BXII & $\mathbf{2 8 4 . 4 6 2 6 , ~ 2 8 4 . 6 3 4 , ~ 2 8 9 . 0 4 3 5 , ~ 2 8 6 . 2 8 8 2}$ \\
\hline PR-BXII & $293.0974,293.4452,299.9688,295.8358$ \\
\hline EP-BXII & $291.7877,292.376,300.9496,295.4389$ \\
\hline NH-BXII & $303.0068,303.5951,312.1687,306.658$ \\
\hline EW-BXII & $292.3694,292.9577,301.5313,296.0206$ \\
\hline BXII-BXII & $286.3742,286.9624,295.536,290.0253$ \\
\hline WG-BXII & $293.4625,294.3581,304.9148,298.0265$ \\
\hline
\end{tabular}



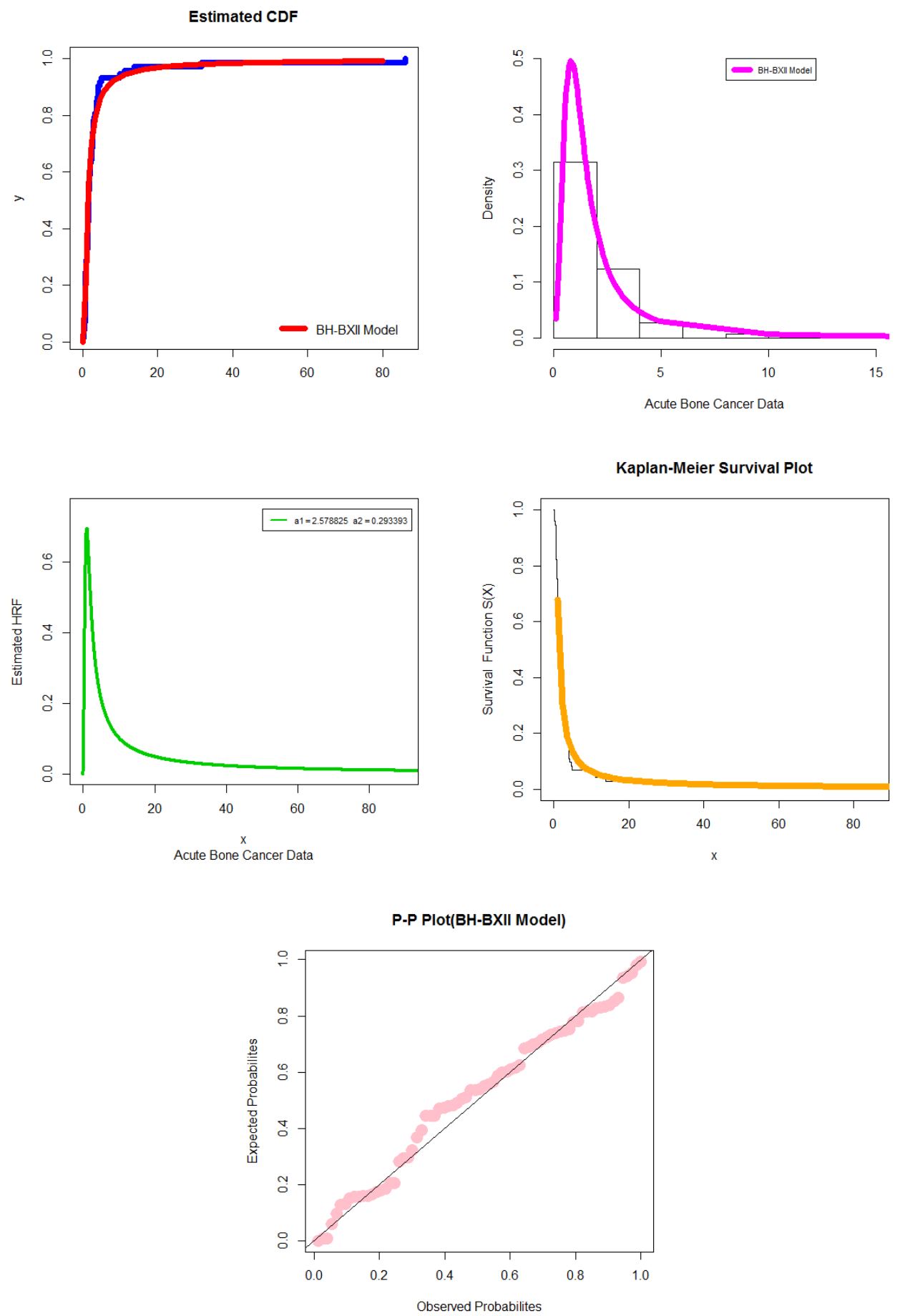

Figure 4: Estimated CDF, PDF, HRF, Kaplan-Meier survival, and P-P plots.

\section{Conclusions}

This paper presented a new two parameter Burr XII distribution. The new PDF can be right skewed with no peak, unimodal-right skewed, left skewed and symmetric. The new HRF can be decreasing, unimodal and increasing. Properties related to the new PDF are derived. Simple type copula-based construction is presented for deriving some new bivariate and multivariate type distributions via the Morgenstern family and the clayton copula. The maximum likelihood estimation, Anderson Darling 
estimation, right tail Anderson Darling estimation and left tail Anderson Darling estimation methods are used to estimate the model parameters. A new data set is analysed for comparing estimations methods and the competitive models.

\section{References}

[1] R. H. M. Abdelkhalek, Extended Poisson-Burr XII Distribution, J. Stat. Appl., 1 (2018), 64-70. 5

[2] M. Aboray, N. S. Butt, Extended Weibull Burr XII Distribution: Properties and Applications, Pak. J. Stat. Oper. Res., 15 (2019), 891-903. 1, 5

[3] A. Z. Afify, G. M. Cordeiro, E. M. M. Ortega, H. M. Yousof, N. S. Butt, The four-parameter Burr XII distribution: properties, regression model, and applications, Comm. Statist. Theory Methods, 47 (2018), 2605-2624.

[4] E. Altun, H. M. Yousof, S. Chakraborty, L. Handique, Zografos-Balakrishnan Burr XII distribution: regression modeling and applications, Int. J. Math. Stat., 19 (2018), 46-70. 1

[5] E. Altun, H. M. Yousof, G. G. Hamedani, A new log-location regression model with influence diagnostics and residual analysis, Facta Univ. Ser. Math. Inform., 33 (2018), 417-449. 1

[6] I. W. Burr, Cumulative frequency functions, Ann. Math. Statistics, 13 (1942), 215-232. 1

[7] I. W. Burr, On a general system of distributions, III.The simplerange, J. Amer. Stat. Assoc., 63 (1968), $636-643$.

[8] I. W. Burr, Parameters for a general system of distributions to match a grid of $\alpha_{3}$ and $\alpha_{4}$, Comm. Statist., 2 (1973), 1-21. 1

[9] I. W. Burr, P. J. Cislak, On a general system of distributions: I. Its curve-shaped characteristics; II. The sample median, J. Amer. Statist. Assoc., 63 (1968), 627-635. 1

[10] G. M. Cordeiro, H. M. Yousof, T. G. Ramires, E. M. M. Ortega, The Burr XII system of densities: properties, regression model and applications, J. Stat. Comput. Simul., 88 (2018), 432-456. 1, 5

[11] M. M. Elbiely, H. M. Yousof, A new flexible Weibull Burr XII distribution, J. Stat. Appl., 2 (2019), 59-77. 5

[12] P. Feigl, M. Zelen, Estimation of exponential survival probabilities with concomitant information, Biometrics, 21 (1965), 826-838.

[13] I. S. Gradshteyn, I. M. Ryzhik, Table of integrals, series, and products, Academic Press, San Diego, (2000). 2.3

[14] M. A. Hatke, A certain cumulative probability function, Ann. Math. Statistics, 20 (1949), 461-463. 1

[15] M. Ibrahim, The compound Poisson Rayleigh Burr XII distribution: properties and applications, J. Appl. Prob. Stat., forthcoming, (2019). 5

[16] A. D. C. Nascimento, K. F. Silva, G. M. Cordeiro, M. Alizadeh, H. M. Yousof, G. G. Hamedani, The odd NadarajahHaghighi family of distributions: properties and applications, Studia Sci. Math. Hungar., 56 (2019), 185-210. 5

[17] P. F. Paranaíba, E. M. M. Ortega, G. M. Cordeiro, M. A. R. de Pascoa, The Kumaraswamy Burr XII distribution: theory and practice, J. Stat. Comput. Simul., 83 (2013), 2117-2143. 2.3

[18] P. F. Paranaíba, E. M. M. Ortega, G. M. Cordeiro, R. R. Pescim, The beta Burr XII distribution with application to lifetime data, Comput. Statist. Data Anal., 55 (2011), 1118-1136.

[19] A. P. Prudnikov, Y. A. Brychkov, O. I. Marichev, Integrals and Series, Vol. 1, Gordon and Breach Science Publishers, Amsterdam, (1986). 2.3

[20] A. P. Prudnikov, Y. A. Brychkov, O. I. Marichev, Integrals and Series, Vol. 4, Gordon and Breach Science Publishers, New York, (1992). 2.3

[21] H. M. Reyad, S. A. Othman, The Top-Leone Burr-XII distribution: Properties and applications, British J. Math. Comput. Sci., 21 (2017), 1-15.

[22] R. N. Rodriguez, A Guide to the Burr type XII distributions, Biometrika, 64 (1977), 129-134. 1

[23] P. R. Tadikamalla, A look at the Burr and related distributions, Internat. Statist. Rev., 48 (1980), 337-344. 1

[24] H. M. Yousof, A. Z. Afify, M. Alizadeh, N. S. Butt, G. G. Hamedani, M. M. Ali, The transmuted exponentiated generalized-G family of distributions, Pak. J. Stat. Oper. Res., 11 (2015), 441-464.

[25] H. M. Yousof, E. Altun, T. G. Ramires, M. Alizadeh, M. Rasekhi, A new family of distributions with properties, regression models and applications, J. Stat. Manag. Syst., 21 (2018), 163-188. 1

[26] H. M. Yousof, E. Altun, M. Rasekhi, M. Alizadeh, G. G. Hamedani, M. M. Ali, A new lifetime model with regression models, characterizations and applications, Comm. Statist. Simulation Comput., 48 (2019), 264-286. 1

[27] W. J. Zimmer, J. B. Keats, F. K. Wang, The Burr XII distribution in reliability analysis, J. Quality Tech., 30 (1998), 386-394. 1, 2.1 